\title{
THE EVALUATION OF QUALITY GOALS AT THE PROCESS LEVEL IN A UNCERTAIN ENVIRONMENT
}

\author{
Hrvoje Puškarić* \\ University of Kragujevac, Faculty of Engineering Sciences, Kragujevac, Serbia \\ Dr Danijela Tadić \\ University of Kragujevac, Faculty of Engineering Sciences, Kragujevac, Serbia \\ Dr Mirjana Misita \\ University of Belgrade, Faculty of Mechanical Engineering, Belgrade, Serbia \\ Dr Miladin Stefanović \\ University of Kragujevac, Faculty of Engineering Sciences, Kragujevac, Serbia \\ Dr Dragan Milanović \\ University of Belgrade, Faculty of Mechanical Engineering, Belgrade, Serbia
}

Improvement of business processes is achieved, among the other, through improvement of quality goals which are defined on the level of each process. In practice, it is not possible to improve all identified quality goals simultaneously. It is assumed that it is necessary that the quality goals values be determined by applying determined metrics. With respect to given values of quality goals, management team determines the order by which quality goals are improved. In this paper, the relative importance of quality goals is stated by fuzzy pair-wise comparison matrix. The performances of quality goals are described by linguistic expressions. All linguistic expressions are modeled by triangular fuzzy numbers. The new model for evaluation of quality goal values with respect to their relative importance is proposed. The developed model is tested by illustrative example with real life data of development process.

Key words: Quality goals, Fuzzy sets, Evaluation

\section{INTRODUCTION}

The analysis and design of enterprise which is based on process approach has been an active area research for many years. The process model of enterprise leads to organizational structure which is absolutely beneficiary oriented and flexible. At the level of each process, aims and responsibilities are uniquely defined and in this way higher control over process resources can be achieved, as well as the interest for accomplishing the identified quality goals which is kind of business goals, etc. Accomplishment of the identified quality goals leads to increasing of competitor's advantage, process improvement, increasing quality of products, etc.

Development process management problem is one of the most important management tasks of quality management, and it can be among the others defined as identification, evaluation and improvement of quality goals. These tasks are implemented in ISO 9000:2000 and ISO 14000 as presented in [13].

In the process of setting goals it is important to point out the following:it is desirable to accomplish management consensus over goals as wide as possible, goals can never be realized without the basic knowledge, it is necessary to be devoted to goal achievement and having too many goals is as bad as not having them at all. Also, it can be possible to apply proposed decision making systems [12], [14, 15, 16]. The solution of this sub-problem affects efficiency and successfulness of process realization.

Measuring the performance or characteristic of quality goals is the second sub-problem of development process management problem. The results which are given by appropriate measure methods enable to observe quality goals better, as well as the efficiency of process management too. In other words, quality goal values enable better understanding of the process, better

* University of Kragujevac, Faculty of Engineering Science, Sestre Janjić 6, 34000 Kragujevac, Serbia; 
control, better delegation of responsibilities, compliance with business goals, determination of efficiency management which is defined as quotient of achieved and projected values of each quality goal. To overview achieved and recognized result.

Based on acquired performance values, quality goal values are calculated. It is highly important to set performance metric system of quality goals.

The process improvement is acquired by increasing the quality goal values. In practice, it is not possible to improve all quality goals in the same time. It is obvious that you should focus efforts to undertake management mesaures first which lead to improvement of quality goals which are associated as the least weighted normalized values.

It is not possible to determine precisely the characteristics of quality goals. Their value is estimated by management team (quality managers, process managers, external experts). These estimations are based on their knowledge, evidence data, current data, etc. It is closer to human reasoning that management team states their evaluations by linguistic expressions more so than by precise values. Development of some areas of mathematics, such as fuzzy set theory [8] enables all uncertainties and vaguenesses to be adequately numerically introduced. In the presence of imprecise, approximate and vague data fuzzy set theory can simulate human way of thinking in the decision making process [07].

The considered problem is solved in two steps. In the first step, the relative importance of quality goals is determined. In many papers which can be find in the literature, the relative weight of considered entitets is stated by pair-wise comparison matrix (by analogy Analytic Hierarchy Process) [17]. In conventional AHP, the pairwise comparison is established by using a standard integer scale (1-9). Value 1 , that is value 9 , denotes that every considered quality goal pair has equal that is extreme importance, respectively. The use of discrete scale of AHP is simple and easy, but it is not sufficient to take into account the uncertainty associated with the mapping of one's perception to a number [10]. Decision makers express their judgments far better by using linguistic expressions than by representing them in terms of precise numbers. It feels more confident to give interval judgments than fixed value judgments.
The relative importance relation of considered values in many papers $[6,19,2]$ is given through comparison pair matrix, where the elements of this matrix are linguistics expressions. The quality weights are determined by applying procedure which is developed in [3].

The evaluation of quality goals and model of business process management selection is possible to realize by applying business planning management (Business Planning Management) (BPM) which leads to significant success of the enterprise. However, it is difficult to systematically and reasonably evaluate business processes for enterprises that plan to introduce BPM [4].

The performance measures for web designed processes are based on numerous indicators of successfulness for different types of processes [20]. The example of industrial implementation shows usage of this metrics as part of the system for monitoring quality of paper factory.

Ratting of dynamic enterprise performance process is based on using sophisticated simulation of the process and optimization tools. Performance evaluation of quality goals represents the base for applying simulation method of processes and researching the possibility of applying optimization tools for re-engineering processes $[21,5]$. In this paper, methodology for evaluation of dynamic enterprise performance process with metrics measurement models is suggested, according to expenses calculation based on activities: Activity Based Costing (ABC) and management based on activities: Activity Based Management (ABM). Prototype software system is implemented in order to validate suggested methodology. Contributions of this paper are the follows: (1) it handles uncertainty in relative importance of quality goals and performance values using fuzzy sets, (2) model for evaluation and ranking of quality goals during the time period is proposed and (2) monitoring of quality goals management efficiency by control cards.

This paper considers: basic assumptions of proposed model, modeling of the relative importance of quality goals and performance values of quality goals, proposed model for ranking of quality goals and verification of proposed models by real-life data which come from developing process. 


\section{THE BASIC ASSUMPTIONS}

The following are assumptions underlying a model of the considered problem:

- Management team (process managers and external experts) identifies quality goals of development process. These quality goals are formally presented by set $C=\{1, \ldots, C, \ldots C\}$. The total number of identified quality goals is denoted as $\mathrm{C}$ and $\mathrm{C}$ is index of quality goal.

- Relative importance of treated quality goals depends on rating of decision makers and, in most cases, hardly changes. Management team evaluations are based on: (a) analysis of historical data based on the experience of other companies, (b) using data which are found in official bulletins, (c) judgments of experts, (d) professional observation, etc. In practice, different approaches are more often combined. Generally, the relative importance of criteria is different and determined according to knowledge and experience of management team. In this paper, the relative importance of each pair of identified quality goals is described by linguistic expression and modeled by triangular fuzzy number.

- Management team defines parameters of quality goals: percentage of deviation, projected time and management resource efficiency. Parameter values are determined by management team by consensus. These values are uncertain and changeable over the period of time. The considered parameters of quality goals can be benefit and cost type. They are described by linguistic expressions which are modeled by triangular fuzzy numbers.

Time period in which development process quality goals values of are evaluated is discretized by discretization step $\Delta \mathrm{t}$. It can be formally presented by set $T=\{1, \ldots, t, \ldots T\}$. The total number time period interval is $T$ and $t$ is index for discretization time period.

\section{MODELLING OF UNCERTAINTIES}

In this Section, modeling of uncertainties in relative importance of quality goals and values of quality goal parameters are described. All uncertainties are described by linguistic expression which is modeled by fuzzy sets [08]. A fuzzy set is represented by its membership function. The parameters of membership function are shape, granularity and location on the universe of dis- course. The membership function of a fuzzy set can be obtained based on one's experience, subjective belief of decision makers, intuition and contextual knowledge about the concept modeled [22]. The triangular fuzzy numbers are most used in the literature. They offer a good compromise between descriptive power and computational simplicity. The range of maximum triangular shape membership has to be around the crisp point of the triangle. Fuzzy sets of higher types and levels have not as yet played a significant role in applications of fuzzy sets theory [09]. Granularity is defined as number of fuzzy numbers assigned to the fuzzy rating of the relative importance and parameter values of quality goals. It can be mentioned that human being can only seven categories at most [11].

\section{MODELING OF QUALITY GOALS WEIGHTS}

Management team determines the number and kind of quality goals of development process primarily depending on the type of industry and size of considered industrial organization.

All the quality goals of development process are usually not of the same relative importance. Also, they can be considered as unchangeable during the considered period of time. They involve a high degree of subjective judgment and individual preferences of decision makers. We think that the judgment of each pair of treated criteria best suits human-decision nature (by analogy with AHP method).

In this paper, the relative importance of each pair of the considered quality goals is described by triangular fuzzy number $\tilde{w}_{\mathrm{cc}^{\prime}}=\left(\mathrm{l}_{\mathrm{cc}}, \mathrm{m}_{\mathrm{cc}}, \mathrm{u}_{\mathrm{cc}}\right)$ ith the lower and upper bounds ${ }_{{ }_{c c}}, u_{c c}$ and modal value , $m_{\text {cc }}$ respectively.

If strong relative importance of quality goal c' over quality goal c holds, then pairwise comparison scale can be represented by the fuzzy number:

$\tilde{W}_{\mathrm{cc}}=\left(\tilde{\mathrm{W}}_{\mathrm{c}^{\prime} \mathrm{c}}\right)^{-1}=\left(\frac{1}{\mathrm{u}_{\mathrm{c}^{\prime} \mathrm{c}}}, \frac{1}{\mathrm{~m}_{\mathrm{c}^{\prime} \mathrm{c}}}, \frac{1}{\mathrm{l}_{\mathrm{c}^{\prime} \mathrm{c}}}\right)$

If $c=c^{\prime}\left(c, c^{\prime}=1, \ldots, C\right)$ then relative importance criterion c over criterion c' is represented by single point 1 which is a triangular fuzzy number $(1,1,1)$.

In this paper, the fuzzy rating of each decision maker can be described by using three linguistic expressions. These linguistic expressions are modeled by triangular fuzzy numbers which are given in the following way: 
- low important - $\tilde{\mathrm{R}}_{1}=(1,1,2.5)$

- moderately important - $\tilde{\mathrm{R}}_{2}=(1,3,5)$

- strongly important - $\mathrm{R}_{3}=(3.5,5,5)$

\section{MODELING OF QUALITY GOAL PARAMETERS}

The parameter values are not measurable values, that it is nearly impossible to be described by precise numbers. Because of that, it is assumed that these values are adequately described by linguistic expressions. Management team determines number and type of linguistic expressions depending on type of enterprises. These linguistic expressions are modeled by triangular fuzzy numbers. The parameter values of quality goals in time period $t$ is modeled by triangular fuzzy number $\sim_{\mathrm{v} p c t}, \mathrm{p}=1, \ldots, \mathrm{P} ; \mathrm{c}=1, \ldots, \mathrm{C} ; \mathrm{t}=1, \ldots, \mathrm{T}$ so that $\tilde{v}_{p c t}=\left(y ; I_{p c t}, m_{p c t}, u_{p c t}\right) \quad$. Lower and upper bounds and modal value of triangular fuzzy number $\quad \tilde{v}_{p c t}, p=1,2,3 ; c=1, \ldots, C ; t=1, \ldots, T \quad$ are denoted as $\mathrm{I}_{\mathrm{pct},} \mathrm{u}_{\mathrm{cpt}}$ and $\mathrm{m}_{\mathrm{pct}}$, respectively.

Domain values are defined on real set numbers into interval (1-9). The value 1 , that is 9 denotes that parameter value has smallest, that is the highest values.

In this paper, the following linguistic expresses are used for describing parameter values:

- low value $-\widetilde{\mathrm{V}}_{1}=(1,1,3)$

- medium value - $\widetilde{V}_{2}=(1,3,5)$

- medium hight value $-\widetilde{V}_{3}=(3,5,7)$

- high value - $\widetilde{\mathrm{V}}_{4}=(5,7,9)$

- very high value $-\widetilde{V}_{5}=(8,9,9)$

\section{THE PROPOSED MODEL FOR EVALUATION QUALITY GOALS}

For management team carrying out the analysis, the following tasks are important: (1) to determine which identified quality goal has the smallest value in time period $t, t=1, \ldots, T$, (2) to determine degree of belief that quality goals are smaller than quality goal which is based at the first place in rank, and (3) quality goals management efficiency with the worst performance to present by relation diagram. Answers to firs two questions are given by comparing triangular fuzzy numbers by using method [1]. Values of quality goals with the worst performance values are visually presented by relation diagram. With the analysis of this diagarm it is possible to determine quality goals efficiency improvement of development process.
Ranking of quality goals depends on their values and relative importance. The relative importance of quality goals is stated as pair-wise comparison matrix. The elements of this matrix are linguistic expressions which are modeled by triangular fuzzy numbers. The weight of each identified quality goal $c, c=1, \ldots, C$ is calculated as average value of all triangular fuzzy numbers of row $c, c=1, \ldots, C$. The calculated value of quality goal weight is described by triangular fuzzy number according to fuzzy rules algebra [08].

In general, treated performance of quality goals can be benefit and cost type. Their values are normalized by using linear normalization procedure [18]. In this way, parameter values are mapped into interval $(0-1)$. Value 0 , that is 1 denotes that parameter value has the smallest, that is the highest value. The normalized values of parameters are presented by triangular fuzzy numbers $\widetilde{r}_{p c t}=\left(y ; L_{p c t}, M_{p c t}, U_{p c t}\right)$. It is assumed that quality goal is consisted of three performances, and then the values of quality goals can be presented graphically by polyhedron. It is assumed that, the value of each quality goal can be presented by volume of polyhedron, $v_{c t}=\Pi_{p=1,2,3} 2 M_{p c t}$ The weighted normalized value of quality goal $c, c=1, ., C$ is denoted as $\widetilde{d}_{c t}=\left(y ; l_{c t}, m_{c t}, u_{c t}\right)$. The rank of quality goals in each time period $t, t=1, \ldots, T$ corresponds to rank of triangular fuzzy numbers $\widetilde{d}_{c t}$. First, $\widetilde{d}_{c t}$ with the smallest value, $m_{c t}$ is found. The quality goals are ranked in increasing order of their modal value $m_{c t}, c=1, \ldots C ; t=1 \ldots, T$. The first in the sequence is $\widetilde{d}_{c t}$. These ranked triangular fuzzy numbers are further analyzed to determine a measure of belief that one fuzzy number is smaller than the other one and a measure of belief that it is not. This procedure is applied in order to determine the measure of belief that a fuzzy number, which is ranked higher, is smaller than another fuzzy number which has a lower rank position.

The algorithm for ranking of quality goals development process is formally given as follows.

Step 1. The pair-wise comparison matrix of the relative importance of quality goals is stated:

$\widetilde{\mathrm{W}}=\left[\tilde{\mathrm{w}}_{\mathrm{cc}}\right]_{\mathrm{CXC}}$

The relative importance of quality goal $c, c=1, . ., C$ is given: 


$$
\tilde{\mathrm{w}}_{\mathrm{c}}=\frac{1}{\mathrm{C}} \cdot \sum_{\mathrm{c}=1}^{\mathrm{C}} \tilde{\mathrm{W}}_{\mathrm{cc}}{ }^{\prime}, \mathrm{c}=1, . ., \mathrm{C}
$$

Step 2. To normalize parameter values by using linear normalization procedure [18]:

a) For benefit type of quality goal parameter:

$$
\tilde{r}_{\text {pct }}=\left(\frac{l_{\text {pct }}}{U^{*}}, \frac{m_{\text {pct }}}{U^{*}}, \frac{\mathrm{u}_{\mathrm{pct}}}{\mathrm{U}^{*}}\right)
$$

b) For cost type of parameter:

$$
\tilde{r}_{\text {pct }}=\left(\frac{1^{-}}{u_{\text {pet }}}, \frac{1^{-}}{m_{\text {pct }}}, \frac{1^{-}}{1_{\text {pet }}}\right) \text {, }
$$

where:

$$
\mathrm{u}^{*}=\max _{\mathrm{p}=1, . ., \mathrm{P}} \mathrm{u}_{\mathrm{pet}}, \mathrm{I}^{-}=\min _{\mathrm{p}=1, . ., \mathrm{P}} \mathrm{l}_{\text {pet }}
$$

Step 3 . To determine quality goal value c, $\mathrm{c}=1, \ldots, \mathrm{C}$ in time period $\mathrm{t}, \mathrm{t}=1, \ldots, \mathrm{T}$ :

$$
\mathrm{v}_{\mathrm{ct}}=\left|\begin{array}{ccc}
\mathrm{m}_{1 \mathrm{ct}} & \mathrm{m}_{2 \mathrm{ct}} & 0 \\
\mathrm{~m}_{1 \mathrm{ct}} & 0 & \mathrm{~m}_{3 \mathrm{ct}} \\
0 & \mathrm{~m}_{2 \mathrm{ct}} & \mathrm{m}_{3 \mathrm{ct}}
\end{array}\right|=2 \cdot \mathrm{m}_{1 \mathrm{ct}} \cdot \mathrm{m}_{2 \mathrm{ct}} \cdot \mathrm{m}_{3 \mathrm{ct}}
$$

Step 4. Calculate weighted normalized quality goal values. By using method which is proposed in [1], the rank of quality goals are determined. The rank of quality goals corresponds to rank of fuzzy numbers.

Step 5. Calculate degree of belief that quality goals can be stated in the first place of determined rank.

Step 6. Determine representative scalar of fuzzy number, $\mathrm{d}_{\mathrm{c}^{*} \mathrm{t}}, \mathrm{d}_{\mathrm{ct}}$ in time period $\mathrm{t}, \mathrm{t}=1, \ldots, \mathrm{T}$. The change of values of each quality goal during the considered time period is presented by relation diagram.

\section{THE ILLUSTRATED EXAMPLE}

In this paper, the proposed procedure is illustrated by example with real-life data of development process of one food company exists in Šumadia region. In this company work about 50 employees. According to size criterion, the considered enterprise is small and medium type. The standards ISO 9001 and ISO 22000 are implemented in this food company by Quality Center of the Faculty of Engineering, Kragujevac. The development process of this food company is one of the most complex business processes. Management of this business process is the most im- portant task of management. The solution of this problem has an impact on growth, development and endurance of the enterprise on the market. The identified quality goals are: on the time delivery $(c=1)$, fulfillment of initial demands of the project $(c=2)$, and engagement of employees $(c=3)$. The parameters of these quality goals are: percentage deviation $(p=1)$, projected time $(p=2)$, and efficient management resources $(p=3)$. First two parameters are cost type and the third considered parameter is benefit type.

The fuzzy pair-wise comparison matrix of the relative importance of quality goals of development process is:

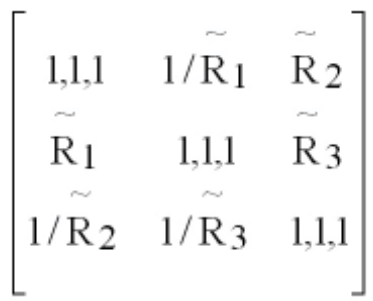

The parameter values are presented in Table 1. The considered period is three months (one quarter). By applying proposed Algorithm (Step 1)., the weights of quality goals are calculated:

$\mathrm{w}_{1}=(0.8,1.67,2.33), \mathrm{w}_{2}=(1.83,2.33,2.83)$ and

$\mathrm{w}_{3}=(0.47,0.51,0.76)$

By applying Algorithm (Step 2 and Step 6) the weighted normalized values of quality goal parameter and their representative scalar for each time period are calculated and presented in Table 2.

Table 1: Parameter values of quality goals for each time period

\begin{tabular}{|c|c|c|c|}
\hline & $\mathrm{c}=1$ & $\mathrm{c}=2$ & $\mathrm{c}=3$ \\
\hline $\mathrm{p}=1$ & $\widetilde{\mathrm{V}}_{2}, \widetilde{\mathrm{V}}_{3}$ & $\widetilde{\mathrm{V}}_{4}, \widetilde{\mathrm{V}}_{3}$ & $\widetilde{\mathrm{V}}_{2}, \widetilde{\mathrm{V}}_{3}$ \\
& $\widetilde{\mathrm{V}}_{2} \widetilde{\mathrm{V}}_{1}$ & $\widetilde{\mathrm{V}}_{5}, \widetilde{\mathrm{V}}_{2}$ & $\widetilde{\mathrm{V}}_{2}, \widetilde{\mathrm{V}}_{1}$ \\
\hline $\mathrm{p}=2$ & $\widetilde{\mathrm{V}}_{4}, \widetilde{\mathrm{V}}_{5}$ & $\widetilde{\mathrm{V}}_{3}, \widetilde{\mathrm{V}}_{3}$ & $\widetilde{\mathrm{V}}_{3}, \widetilde{\mathrm{V}}_{2}$ \\
& $\widetilde{\mathrm{V}}_{2}, \widetilde{\mathrm{V}}_{4}$ & $\widetilde{\mathrm{V}}_{5}, \widetilde{\mathrm{V}}_{2}$ & $\widetilde{\mathrm{V}}_{4}, \widetilde{\mathrm{V}}_{1}$ \\
\hline $\mathrm{p}=3$ & $\widetilde{\mathrm{V}}_{2}, \widetilde{\mathrm{V}}_{2}$ & $\widetilde{\mathrm{V}}_{3}, \widetilde{\mathrm{V}}_{2}$ & $\widetilde{\mathrm{V}}_{3}, \widetilde{\mathrm{V}}_{2}$ \\
& $\widetilde{\mathrm{V}}_{1}, \widetilde{\mathrm{V}}_{2}$ & $\widetilde{\mathrm{V}}_{2}, \widetilde{\mathrm{V}}_{3}$ & $\widetilde{\mathrm{V}}_{3}, \widetilde{\mathrm{V}}_{3}$ \\
\hline
\end{tabular}


The least weighted normalized value in time period $t=1$ is quality goal engagement of employees $(c=3)$. With respect the given results (see Table 1), it can be concluded that management team should undertake management measures which lead to improvement of denoted quality goal values Table 3.

In the second quarter, the quality goal on the time delivery $(c=1)$ has the least weighted normalized value. Degree of belief that performance of quality goal engagement of employees $(c=3)$ have lower values than performance on the time delivery $(c=1)$ is 0.96 . Management team has to undertake appropriate measures to improve performance values of both analyzed quality goals almost simultaneously Table 4.

In the third quarter, quality goal fulfillment of initial demands of project $(c=2)$, has the lowest weighted normalized value. Management team in considered time period should focus its attention on possibility of improvement of this quality goal Table 5.

Table 2: The rank of quality goals of development process in time period $t=1$

\begin{tabular}{|c||c|c|c|c|}
\hline $\begin{array}{c}\text { Quality } \\
\text { goals }\end{array}$ & $\begin{array}{c}\text { The weighted normalized } \\
\text { quality goal values }\end{array}$ & Rank & $\begin{array}{c}\text { Degree of belief that quality goal } \\
\text { can be placed in the first place of } \\
\text { the rank }\end{array}$ & $\begin{array}{c}\text { The representative } \\
\text { scalar values }\end{array}$ \\
\hline $\mathrm{c}=1$ & $\widetilde{\mathrm{d}}_{11}=(0.0254,0.0529,0.0739)$ & 2 & 0.305 & 0.0529 \\
\hline $\mathrm{c}=2$ & $\widetilde{\mathrm{d}}_{21}=(0.058,0.0739,0.0897)$ & 3 & 0 & 0.0739 \\
\hline $\mathrm{c}=3$ & $\widetilde{\mathrm{d}}_{31}=(0.0209,0.0226,0.0387)$ & 1 & 1 & 0.0226 \\
\hline
\end{tabular}

Table 3: The rank of quality goals of development process in time period $t=2$

\begin{tabular}{|c||c|c|c|c|}
\hline $\begin{array}{c}\text { Quality } \\
\text { goals }\end{array}$ & $\begin{array}{c}\text { The weighted normalized } \\
\text { quality goal values }\end{array}$ & Rank & $\begin{array}{c}\text { Degree of belief that quality goal } \\
\text { can be placed in the first place of } \\
\text { the rank }\end{array}$ & $\begin{array}{c}\text { The representative } \\
\text { scalar values }\end{array}$ \\
\hline $\mathrm{c}=1$ & $\widetilde{\mathrm{d}}_{12}=(0.0178,0.0371,0.0517)$ & 1 & 1 & 0.0371 \\
\hline $\mathrm{c}=2$ & $\widetilde{\mathrm{d}}_{22}=(0.0489,0.0622,0.0756)$ & 3 & 0.1 & 0.0622 \\
\hline $\mathrm{c}=3$ & $\widetilde{d}_{32}=(0.0348,0.0378,0.0563)$ & 2 & 0.96 & 0.0378 \\
\hline
\end{tabular}

Table 4: The rank of quality goals development process in time period $t=3$

\begin{tabular}{|c|c|c|c|c|}
\hline $\begin{array}{c}\text { Quality } \\
\text { goals }\end{array}$ & $\begin{array}{c}\text { The weighted normalized } \\
\text { quality goal values }\end{array}$ & Rank & $\begin{array}{c}\text { Degree of belief that quality goal } \\
\text { can be placed in the first place of } \\
\text { the rank }\end{array}$ & $\begin{array}{c}\text { The representative } \\
\text { scalar values }\end{array}$ \\
\hline $\mathrm{c}=1$ & $\widetilde{\mathrm{d}_{13}}=(0.0198,0.0412,0.0576)$ & 3 & 0.13 & 0.0412 \\
\hline $\mathrm{c}=2$ & $\widetilde{\mathrm{d}}_{23}=(0.015,0.0191,0.0232)$ & 1 & 1 & 0.0191 \\
\hline $\mathrm{c}=3$ & $\widetilde{\mathrm{d}}_{33}=(0.0249,0.0269,0.0402)$ & 2 & 0 & 0.0269 \\
\hline
\end{tabular}

Table 5: The rank of quality goals of development process in time period $t=4$

\begin{tabular}{|c|c|c|c|c|}
\hline $\begin{array}{c}\text { Quality } \\
\text { goals }\end{array}$ & $\begin{array}{c}\text { The weighted normalized } \\
\text { quality goal values }\end{array}$ & Rank & $\begin{array}{c}\text { Degree of belief that quality goal } \\
\text { can be placed in the first place of } \\
\text { the rank }\end{array}$ & $\begin{array}{c}\text { The representative } \\
\text { scalar values }\end{array}$ \\
\hline $\mathrm{c}=1$ & $\widetilde{\mathrm{d}}_{14}=(0.0762,0.1589,0.2218)$ & 1 & 1 & 0.1589 \\
\hline $\mathrm{c}=2$ & $\widetilde{\mathrm{d}}_{24}=(0.2258,0.2875,0.3492)$ & 2 & 0 & 0.2875 \\
\hline $\mathrm{c}=3$ & $\widetilde{\mathrm{d}}_{34}=(0.5222,0.5667,0.8444)$ & 3 & 0 & 0.5667 \\
\hline
\end{tabular}


In the last of considered quarter, the quality goal on the time delivery $(c=1)$, has the least weighted normalized value. Management team should make an effort to undertake and monitor management measures which lead to improvement of this quality goal.

The representative scalars of quality goals values for each considered time period are presented by relation diagrams Figure 1., Figure 2. and Figure 3.

\section{C1}

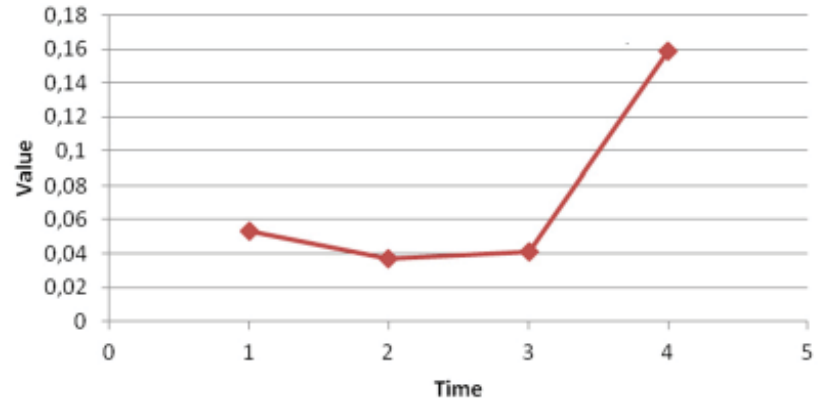

Figure 1: The weighted normalized values of on the time delivery $(c=1)$ during the time period

\section{C2}

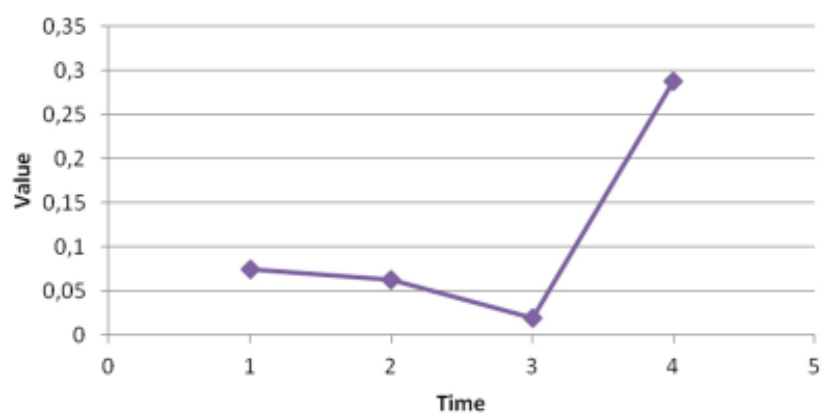

Figure 2: The weighted normalized values of initial demands fulfillment of project $(c=2)$ during the time period

\section{C3}

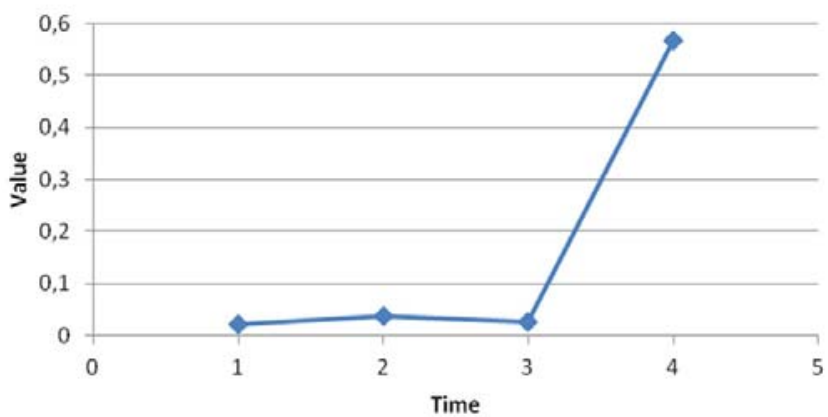

Figure 3: The weighted normalized values of engagement of employees $(c=3)$ during the time period

According to relation diagrams it can be concluded that values of each identified quality goal in first three quarters have almost same values. In the last quarter value of each quality goal is significantly increasing. According to given results, management measures taken are adequate and lead to increasing of quality goal values which further enables improvement of considered business process.

\section{CONCLUSION}

The evaluation of quality goals on the business process level is important task of management team. Improvement of business processes depends on the solution of considered problem. Consequently, a fuzzy logic based approach appears as a natural way to describe vagueness of effects parameters of quality goals.

The proposed fuzzy model contributes to forming an opinion which quality goal has the lowest value in considered time period. Finding the degrees of belief that a quality goal has a higher predisposition to have the worst value than some other quality goals, helps management team to recommend the application of specific management measures.

The proposed model was tested on a randomly selected group of quality goals which are given from the telecommunication enterprise in Republic Serbia. The results obtained by using real world examples showed good performance of the new model. The propsed model is very flexible in the sense that it can be easily extended to include more quality goals.

\section{REFERENCES}

1) Bass, M.S., Kwakernaak, H. (1977). Rating and Ranking of Multiple-aspect Alternatives using Fuzzy sets. Automatica, 3, 47-58.

2) Chan, S.T.F., Kumar, N. (2007). Global supplier development considering risk factors using fuzzy extended AHP-based approach. Int. Journal of Production Research, 46, 417-431.

3) Chang, D.Y. (1996). Applications of the extent analysis method on fuzzy AHP. European Journal of Operational Research, 95, 649-655.

4) Chiwoon C., Seungsin, L. (2010) A study on process evaluation and selection model for business process management. School of Industrial Engineering, University of Ulsan, Ulsan 680-749.

5) Gaben. M., Krčevinac. S., Vujošević. M. (2007): Modelujući sistemi u optimizaciji. Journal of Applied Engineering Science, No.18, pp. 37-46. 
6) Gumus, T.A. (2009). Evaluation of hazardous waste transportation firms by using a two step fuzzy-AHP and TOPSIS methodology. Expert System with Applications, 36, 4067-4074.

7) Kaur, P., Chakrabortyb, S. (2007). A New Approach to Vendor Selection Problem with Impact Factor as an Indirect Measure of Quality. Journal of Modern Mathematics and Statistics, 1, 1-8.

8) Klir, G.J., Folger, T.A. (1988) Fuzzy Sets, Uncertainty and Information (1st ed.). New Yersy: Prentice-Hall.

9) Klir G.J., Yuan, B. (1995) Fuzzy sets and fuzzy logic, theory and applications. Prentice Hall. New Jersey.

10) Kwong, C.K., Bai, H. (2003). Determining the importance weights for the customer requirements in QFD using a fuzzy AHP with an extent analysis approach. IIE Transakcions, 35 (7), 619-625.

11) Lootsma, F.A. (1997) Fuzzy Logic for Planning and Decision making. Kluwer Academic, Boston, USA.

12) Milanović, D., Ranđić. D., Ristić. Lj.(2007): Unapređenje sistema upravljanja životne sredine po standardima ISO14000, Journal of Applied Engineering Science, No. 18, pp. 7-12.

13) Milosavljević, Đ. (2003): “Unapređenje sistema upravljanja životne sredine po standardima" Journal of Applied Engineering Science, Vol. 1, No. 1, pp. 41-48.

14) Misita. M., Senussia. G., Milovanović. M.(2012): A combining genetic learining algorithm and risk matrix model using in optimal production program" Journal of Applied Engineering Science, Vol. 10, No. 3, pp. 147-152

15) Nunes. I.(2012): "Fuzzy systems to support industrial engineering management", Journal of Applied Engineering Science, No. 3, Vol. 10 , No. 3, pp. 143-146
16) Popović. M., Vasić. B., Curović. D.(2010): A possible answer to the question: What is asset management? Journal of Applied Engineering Science,Vol. 8, No.4, pp. 205-2014

17) Saaty, T.L. (1990). How to make a decision: The Analytic Hierarchy Process. European J. Oper., 489-26.

18) Shih, H.S., Shyur, H.J., Lee, E.S. (2007). An Extension of TOPSIS for Group Decision Making. Mathematical and Computer Modelling, 45, 801-813.

19) Tadić, D., Milanović, D., Misita, M., Tadić, B. (2011). New integrated approach to the problem of ranking and supplier selection under uncertainties. Proceedings of the Institution of Mechanical Engineers. Part B: Journal of Engineering manufacture, 225, 1713-1724.

20) Vesa, H., Heikki, K. (2011) Performance metrics for web-forming processes, Aalto University School of Electrical Engineering, Department of Automation and Systems Technology, P.O. Box 15500, 00076.

21) WenAn T., Weiming S., Jianmin Z. (2006) A methodology for dynamic enterprise process performance evaluation, a Software Engineering Institute. Zhejiang Normal University, JinHua, Zhejiang, 321004, PR China.

22) Zimmermann, H.J. (1978). Results of empirical studies in fuzzy set theory (ed. G.J. Klir). Applied General Systems Research, Plenum Publishing Corporation, 303-311.

Paper sent to revision: 31.01.2013.

Paper ready for publication: 05.03.2013. 